2

\title{
DE LA MEMORIA DEL PROYECTO*
}

"El relato es la dimensión lingüística que proporcionamos a la dimensión temporal de vida, de la cual podemos hablar indirectamente gracias a la poética del relato. La historia de la vida se convierte, de ese modo, en una historia contada..."

Paul Ricoeur

"El pensamiento humano posee un aspecto realizativo, concretamente comprometido con las materias y con las técnicas (...) y un aspecto procesual y 'tentativo', típico de un hacer que mientras hace inventa el modo de hacer..."

Luigi Pareyson

* Publicado en De Signos y Sentidos. Travesías del sentido / Indagaciones Narrativas. Año 1, No 1. Santa Fe, Ediciones UNL, 2004, pp. 39-67. 


\section{EL PROYECTO EN PERSPECTIVA}

El presente proyecto corresponde a la séptima fase (2000-2004) de un programa general o línea promocional de desarrollo sobre investigaciones semióticas aplicadas ${ }^{1}$ que, con la denominación inicial de Semiótica y pedagogía del espectáculo y mi dirección, continúa ejecutándose en el ámbito de la Facultad de Humanidades y Ciencias de la Universidad Nacional del Litoral, desde el segundo semestre del año 1987 . Dicho proyecto general se ha venido desenvolviendo de acuerdo con una programación en sucesivas etapas ${ }^{2}$, las cuales fueron oportunamente evaluadas por comisiones externas y aprobadas por los organismos pertinentes de la Facultad y la Universidad.

En sus tramos iniciales (1987-1990), explícitamente vinculados con la interacción semiótica-espectáculo (1987-1989: Tramo I. El teatro y las posibilidades de la transposición: intertextualidad y reproducción del sentido; 1989-1990: Tramo II. El acontecimiento teatral y los mecanismos de recepción en la práctica espectacular), se produjeron resultados relacionados con la orientación de los siguientes objetivos: (a) Sistematización y análisis sincrético de propuestas existentes, y producción de aportes en orden a la consolidación de la (todavía, entonces) incipiente semiótica del espectáculo. (b) Transferencia y producción de conocimientos en orden a un mejoramiento de lo existente en materia de metodología educativa (propuestas, por ejemplo, sobre aprovechamiento didáctico de medios y recursos acerca de la posible identidad del espectáculo santafesino, desde una doble perspectiva: sincrónica o descriptiva, y diacrónica o histórica ${ }^{3}$.

\footnotetext{
${ }^{1}$ Respecto de los correspondientes códigos de identificación y adscripción del proyecto cfr. (a) Disciplina científica: Lenguajes en relación con otros campos (Cód. 4707); (b) Campos de Aplicación: Promoción del conocimiento en Ciencias Humanas y Sociales (Códs. 1150/1160); (c) Áreas temáticas: semiótica textual- estudios narratológicosenseñanza e investigación social.

${ }^{2}$ Las reseñas de este capítulo constituyen la sinopsis de un relato investigativo en preparación, de próxima publicación en estos cuadernos. En 1997, a los diez años del proyecto, apareció una primera versión del mismo en la Revista Estudios Sociales (Año VII - N013). Cfr. "Intervenciones, proyectos y prácticas en el espacio semiótico del dominio sociocultural (1987-1997)", págs. 167-180.

${ }^{3}$ Parte de la producción de este primer período se registra en el volumen Literatura y espectáculo. La transposición, de AAV, publicado en octubre de 1991 (Santa Fe: UNL - Colección Ciencia y Técnica. 256 págs, ISBN 950-9840-30-0).
} 
En los tramos siguientes (1990-1996), relacionados con la exploración de posibles implicaciones y mutuos aprovechamientos entre perspectivas semióticas y prácticas educativas (1990-1991: Tramo III. Modelos didácticos de transposición semiótica y prácticas espectaculares; 1992-1993: Tramo IV. Acontecimientos y estrategias espectaculares en las situaciones de enseñanza y aprendizaje y 1994-1996: Tramo V. Perspectivas semióticas y aprovechamientos didácticos en el campo de las interacciones discursivas; con alcances y derivaciones en los proyectos siguientes), se obtuvieron aportes vinculados con los siguientes propósitos: (1) Delimitación del acontecimiento didáctico como espacio de intercambios discursivos (heterogeneidad de configuraciones del sentido/ diversidad de dominios de significación), en el que la noción de espectáculo opera como categoría implícita, intersticial. (2) Confrontación de variantes (estrategias espectaculares): la indagación de mecanismos discursivos, estudio de comportamientos y propiedades actorales, determinación de proyectos enunciativos y tipos de ritualizaciones emergentes, etc., que permitieran inferir núcleos invariantes de una matriz textual específica, inherente al sistema educativo. (3) Sistematización de contribuciones y desarrollo de modelos didácticos, con base semiótica, para (a) referir estrategias significativas y representativas del discurso de las prácticas docentes, (b) describir e interpretar textos de diferente soporte significante, y (c) recrear y construir nuevos textos. (4) Formalización de propuestas didácticas, en campos específicos de aplicación de las áreas disciplinares de la comunicación y la expresión.

Aunque en la misma dirección exploratoria de implicaciones existentes entre prácticas semiótica y didáctica, los proyectos elaborados y ejecutados en la etapa siguiente (1996 - 1999: Tramo VI), previa a la actual, se orientaron hacia el tratamiento de posibles interacciones y transposiciones en el ámbito de las ciencias sociales, en procura de dar cuenta (por ejemplo) de las particularidades discursivas y las modalidades textuales con que opera la construcción historiográfica, los procesos significativos implícitos en la noción de espacio / paisaje geográfico, etc. ${ }^{4}$

\footnotetext{
${ }^{4}$ En referencias anteriores y otras notas aclaratorias que aparecen a continuación se profundiza en el desarrollo y alcances de esta penúltima etapa del proyecto general.
} 


\subsection{ACERCA DE LA INVESTIGACIÓN SEMIÓTICA Y DIDÁCTICA}

Reflexionar hoy, sin embargo, acerca de las singularidades e improntas de la enseñanza de un determinado campo disciplinar, supone concebir una didáctica interesada en encarar (explícitamente) aspectos inherentes a la particularidad de los contenidos con los que debe operar, y dispuesta a resolver (de manera simultánea) problemas que procuren dar respuesta a diferentes interrogantes conectados con un complejo entramado de cuestiones. Algunas de dichas problemáticas podrían referenciarse en relación con la particular entidad epistemológica del campo disciplinar específico(la naturaleza de sus conocimientos, el carácter mismo de sus contenidos, sus posibilidades de abordarlos y modos de integrarlos, etc.). Otras, con imperativos no menos dificultosos, que se vinculan con modalidades propias de la transposición didáctica de tales saberes (delimitar recortes y desarrollar criterios para la selección de contenidos, estrategias de enseñanza, producción de materiales o recursos...), en tanto que añaden a la complejidad de los contenidos específicos (del campo disciplinar) y a la complejidad del objeto específico de su didáctica (la enseñanza del campo disciplinar), "el controvertido carácter epistemológico de la didáctica misma como disciplina" (Camilloni, 1994: 26).

Es que la didáctica y la semiótica, la identidad constitutiva de sus dominios particulares y la delimitación de sus respectivos objetos, históricamente han generado profusas controversias e inusitados debates. Si bien la dificultosa situación en uno y otro campo obedece a razones diferentes, las mismas se relacionan en general con improntas de una concepción micro o macrodisciplinar en cada caso, derivadas de sus propios orígenes: cierta visión artesanal de lo didáctico, esbozos suprateóricos de índole preliminar en lo semiótico.

Por diversas causas, de algún modo conectadas con marcos epistemológicos de raíz positivista, estos rasgos fundacionales continuaron impactando en posteriores desarrollos, incluso en la didáctica y la semiótica actuales, insinuando también curiosas afinidades entre ambos campos, más allá de sus específicos contextos de desenvolvimiento.

Ambas se continúan vinculando, por ejemplo, en su consideración habitual, como prácticas ideológicas que, para constituirse en dominios científicos, debieron incorporar teorizaciones de distintos campos de las ciencias sociales, y que aún necesitan nutrirse de otras indagaciones para poder avanzar en sus 
proyectos teóricos propios. Asimismo porque, sin desdeñar o descuidar aquellos singulares aportes, demandan la profundización de sus conocimientos a través de investigaciones específicas, respectivamente enfocadas desde una u otra orientación disciplinar.

Sin embargo, lo cierto es que se siguen adoptando criterios diferenciales, con frecuencia condicionados por fuertes prejuicios y creencias, a la hora de considerar los modos en que uno y otro campo entroncan la construcción de sus saberes. A diferencia de la semiótica, se suele seguir definiendo a los conocimientos del dominio didáctico, como específicamente normativos y prescriptivos, con escasa o nula proyección científica, ya que sólo parecieran apuntar a resolver situaciones prácticas que satisfagan tales requerimientos.

Esta concepción racionalista y tecnológica no sólo simplifica objetos e intereses tan complejos como la construcción y la enseñanza, desde el ámbito institucional hasta la clase, el planeamiento escolar o la formación docente inicial y continua, sino que convierte al campo de la didáctica en un conjunto cuestiones unívocas, de saberes meramente instrumentales, consistentes en la aplicación de fórmulas y técnicas entendidas como universales válidos, en tanto se sustenten en conocimientos científicos predeterminados (cfr. Camilloni, 1994, 1997; Litwin, 1995, 1997).

Dicha perspectiva, según la cual la didáctica debiera ocuparse sólo de generar normatividades para la tarea docente o de encarar la solución de problemas específicos de la enseñanza, se contrapone con actuales reflexiones críticas e investigaciones comprometidas con una comprensión totalizadora de los fenómenos educativos y de sus procesos de comunicación e interpretación. Al superar aquella posición instrumentalista, esta conceptualización diferente de la didáctica contribuye a construirla como disciplina científica del campo social, toda vez que sus conocimientos específicos ya contarían con suficientes condiciones de validación y justificación: supuesto esencial, reconceptualizador de lo didáctico, con el cual se viene comprometiendo la orientación de nuestro trabajo en el Proyecto.

El enfoque adoptado a propósito del dominio semiótico se relaciona, en cambio, con una perspectiva diversa de este esfuerzo por remontarse desde la visión instrumental hacia un ámbito de reflexión teórica, que supone el itinerario reconstitutivo del campo didáctico. En efecto, los estudios semióticos se asocian a menudo con cuestiones o problemas referidos a saberes exclusiva- 
mente teóricos, con objetos y tratamientos de compleja formulación y dificultosa transferencia. También suele caracterizarse como escasa su rentabilidad, respecto de posibles aplicaciones prácticas, e improbables sus resultados, en términos de transformaciones efectivas de la "realidad concreta".

El trabajo diseñado en nuestro Proyecto también parte, en este caso, de otros supuestos, en buena medida contrarios a los que establecen dichas opiniones y prejuicios. Se postula, por ejemplo, afirmativamente que:

> el hacer semiótico puede ser entendido como una forma de praxis, por lo menos en el campo educativo (aunque, ciertamente, hacemos extensiva esta concepción a otros dominios de las ciencias humanas y sociales);

$>$ así como la investigación semiótica puede sumar contenidos específicos a los saberes de las ciencias relacionadas con el fenómeno de la educación, las prácticas educativas concretas, situadas en el contexto de la institución y la actividad escolar, pueden transformarse en objetos privilegiados de análisis para el avance del proyecto semiótico; $>$ la intervención semiótica, en los campos de la enseñanza y la investigación didáctica por ejemplo, permitiría efectuar aportes de consideración para el replanteo de estados o situaciones, algunos de ellos (incluso) con impacto más o menos inmediato.

\subsection{LOS DOS TRAMOS ANTERIORES DEL PROYECTO}

En este marco de referencias conceptuales, el Tramo V (1994-1996) del aquel proyecto general en desarrollo, entonces titulado Perspectivas semióticas y aprovechamientos didácticos ${ }^{5}$ se propuso integrar diferentes objetos de interés y perspectivas de abordaje en relación con la posible especificación de un campo interdisciplinar de indagaciones referidas a la comunicación y la enseñanza: con la construcción de dispositivos textuales y estrategias discursivas para la producción, reconocimiento y negociación de contenidos (re)significados en el campo de las interacciones didácticas.

\footnotetext{
${ }^{5}$ Aprobado por Res. HCS UNL No 184/93 y subsidiado por la Secretaría de Ciencia y Técnica, como proyecto integrante de la Programación CAI+D Pensamiento, lenguaje y semiosis en las prácticas educativas.
} 
Entre otras líneas de investigación trabajadas en esta dirección (y cuyos resultados confluyen en el diseño del actual Proyecto), pueden citarse:

> Algunos aportes tendientes a la reconceptualización de la teoría del currículum, aquí entendido en términos de objeto formal y de constructo cultural, cuya dinámica procesual permite identificar modalidades de estructuración específica, en distintas configuraciones o niveles de la significación textual (del currículum como texto), cada una de ellas con sus propias referencias y transposiciones.

$>$ El relevamiento de cuestiones relacionadas con la naturaleza formal del acontecimiento didáctico, concebido como particular caso de comunicación participativa: las estrategias del funcionamiento de un virtual contrato establecido, la complejidad de los objetos a transmitir a través de la negociación didáctica, los recorridos pragmáticos e interpretativos inmanentes a la sustanciación de un pacto de verosimilitud, etc. > La discusión acerca de diversas aplicaciones que, a modo de propuestas de transposición didáctica, suelen proyectarse en el trabajo del aula a propósito de ciertos sistemas textuales heterogéneos (escriturales, pictóricos, audiovisuales...): ciertos mecanismos de producción y pluralidad de códigos intervinientes en cada específica construcción discursiva, características singulares de su recepción e indicadores pragmáticos implicados en cada uno de tales procesos; etc.

En cuanto al Tramo Vl. Aportes de la semiótica textual a las prácticas discursivas de la historia (1997-1999), se ha definido como propuesta de sistematización e indagación crítica sobre perspectivas semióticas actuales (a su vez articuladas con formulaciones pragmáticas y lingüísticas), con la finalidad de verificar sus posibilidades de aprovechamiento teórico-metodológico y de transferir sus aportes al campo de lo historiográfico y lo didáctico. Las actividades desarrolladas en este caso han partido del supuesto de que, con la constitución de áreas disciplinares que demandan saberes integrados (como la semiótica del texto y algunas orientaciones analíticas y críticas del discurso), sería posible (a) enriquecer el abordaje de la compleja dimensión significante del acontecer histórico a partir de la experiencia codificada, (b) delimitar sus principales modos de operar sobre el soporte contextual de los datos, y (c) tematizar, en diferentes manifestaciones textuales (verbales y no verbales, gráficas, espectaculares...), 
la materialidad discursiva de determinados procedimientos organizativos de selección e interpretación informativa o documental.

Así resignificado el doble anclaje de lo social en el sentido y del sentido en lo social, es posible concebir al dominio de la historia como un privilegiado ámbito disciplinario de interacciones discursivas, las que operan en diferentes direcciones y virtualizando nuevos aprovechamientos: sea como práctica investigativa de la construcción historiográfica, sea como práctica transpositiva de didácticas específicas en el campo.

Tanto el proyecto recién referido ${ }^{6}$, como el tramo actualmente en fase final de ejecución: Semiótica, enseñanza e investigación ${ }^{7}$, ya se desarrollaron en conjunción con otros proyectos del Centro de Estudios Sociales Interdisciplinarios del Litoral (CESIL), que tiene su sede en la Facultad de Humanidades y Ciencias de la Universidad del Litoral.

De las articulaciones e integraciones establecidas durante el desarrollo de ambas propuestas investigativas, y en el marco de sus interacciones con otros proyectos afines de los referidos programas de investigación, ha surgido el diseño y planeamiento de un nuevo proyecto (octava fase o tramo perteneciente al lineamiento general), para ser ejecutado durante el próximo período 2005-2007.

\subsection{SOBRE IMPACTOS Y NUEVAS PERSPECTIVAS}

En la confluencia de aportes de diferentes proyectos desarrollados en los últimos años (en relación con unas y otras contribuciones ${ }^{8}$ referidas a la línea de investi-

\footnotetext{
${ }^{6}$ Que se iniciara en 1997, en interacción con otros diseños correspondientes al Programa CAI+D 96 sobre Estudios interdisciplinarios de historia social, aprobado por Res. HCS UNL N74/97.

${ }^{7}$ Del Programa CAI+D 2000 sobre Estudios de las relaciones entre discurso y sociedad, aprobado por Res. HCS UNL N0127/99.

${ }^{8}$ De las orientaciones y sucesivos avances o aportes formulados en esta misma dirección ha venido dando cuenta buena parte de la producción bibliográfica del Proyecto en estos últimos años. Por mi parte, a través de dos publicaciones en colaboración: C. Caudana y E. Ghio (dirs.) (1995): Lenguajes y prácticas educativas, Santa Fe, UNL / Centro de Publicaciones, ISBN 950-9840-62-9; y (1997a): Decir, hacer, enseñar. Semiótica y pragmática discursiva, Santa Fe, UNL / Centro de Publicaciones (Colección Ciencia y Técnica), 184 págs., ISBN 987-508-0063; y con distintos trabajos, ensayos y artículos publicados en diferentes medios. Entre otros: (1994) "Reflexiones sobre semiótica y campo cultural", en Revista Enlace Universitario. Año III-Nº 3. Universidad Estatal de Bolívar / Ecuador, julio de 1994, págs. 157-170. (1997b): "Para una morfología del discurso didáctico", en Cuadernos de
} 
gación semiótica en curso), se fue fortaleciendo nuestra convicción de que, en un contexto de progresiva complejización de los procesos educativos, de demandas de mejoramiento de la calidad de la enseñanza y la producción del aprendizaje, de urgencias transformadoras de la "realidad concreta" de la escuela, además de proponer y describir situaciones precisas o de impacto práctico más o menos inmediato, se impone generar desarrollos teóricos que apuntalen necesarias reflexiones críticas sobre (distinto tipo de) cuestiones previas al funcionamiento efectivo, "real" de las prácticas que acontecen en la escena del aula.

Procurando extender (a la vez que consolidar) aquellos soportes, en relación ahora con contribuciones de la perspectiva narratológica aplicada a distintas configuraciones analíticas e interpretativas del campo sociocultural, la agenda de trabajo actual aspira una vez más a desarrollar nuevas posibilidades teóricometodológicas y sus modos de transferencia al campo de la enseñanza, el aprendizaje y la investigación en ciencias humanas y sociales.

Así, en el contexto de sucesivas experiencias, incorporaciones y replanteos acumulados durante el transcurso de todo el proceso de investigación llevado a cabo (desde 1987 a la fecha [2004], pero especialmente en los últimos años), se han venido gestando entonces preocupaciones y cuestiones de interés que, en definitiva, han ido conformando y definiendo perfiles y especificidades de este nuevo proyecto de investigación y desarrollo.

Si se consideran la índole singular del objeto de estudio, y aun los espacios de vacancia que permitirían ofrecer un dominio reflexivo todavía no suficientemente estabilizado o consolidado sobre la cuestión, como el aquí se pretende

la Forma, Año I - No 1, Buenos Aires, Sociedad de Estudios Morfológicos de Argentina, págs. 63-74; (1997c): "Intervenciones, proyectos y prácticas en el espacio semiótico del dominio sociocultural" en Estudios Sociales. Revista Universitaria Semestral, Año VII-No 13, Santa Fe, UNL / Centro de Publicaciones, 200 págs., setiembre de 1997, ISSN 0327-4934, Especialmente págs. 167-180; (1998): Sobre textos y discursos en las construcciones del sentido, Santa Fe, UNL, Secretaría de Extensión y Centro de Estudios de la Facultad. Serie "Temas de Humanidades, No 3, 56 págs.; (1999): La construcción del relato como objeto de la historia. Estrategias referenciales y operatorias narrativas, Santa Fe, UNL, Programa de Estudios Interdisciplinarios de Historia Social. Serie: "Documentos de Trabajo", No 12, 46 págs.; (2002): "La semiosis didáctica. Constituciones, formatos y soportes", en: Texturas. Estudios Interdisciplinarios sobre el Discurso. Año 2- № 2, Santa Fe, Facultad de Humanidades y Ciencias de la UNL (CESIL), ISSN: 1666-8367, págs. 33-59.; (2003) "Discursividades, texturas... polémicas en la historia", en Texturas. Estudios Interdisciplinarios sobre el Discurso, Año 3 - No 3, págs. 23-36. 
(la configuración de un espacio en que semiótica, didáctica e investigación social que armonicen e intercambien sus saberes y conocimientos particulares), se comprenderá que no puedan mensurarse a priori o calcularse en términos proyectivos efectos sociales, científicos, económicos, etc. del tramo en ejecución. Al profundizar y tratar de conciliar perspectivas y postulaciones teórico-metodológicas no siempre convergentes, y que actualmente se debaten e investigan con escasas vinculaciones entre sí, se contribuirá sin embargo a una superación de aquella situación existente.

El desenvolvimiento de la tarea investigativa podrá también contribuir al progreso de la teoría de los discursos sociales, a través de la práctica de enfoques inter y transdisciplinarios, en algunos casos con incipientes desarrollos en nuestro ámbito. Permitirá además esclarecer los presupuestos semióticos que operan en toda práctica educativa, historiográfica, espectacular, audiovisual, en tanto construcciones de sentido que acontecen en un contexto de conformaciones y circulaciones productivas de determinados saberes del campo social.

La explicitación de mecanismos, estrategias, convenciones y representaciones del imaginario social incidirá, específicamente, en la indagación de la problemática polisistémica del fenómeno. Asimismo, de la contrastación de dimensiones, categorías y conceptos propios de la semiótica textual con las respectivas configuraciones discursivas de las ciencias sociales devendrá una instancia superadora de lo existente, que habrá de convertirse en aporte concreto para las prácticas de la enseñanza, el aprendizaje y la investigación en el área disciplinar.

Es decir: el ejercicio interactivo de permutas e intercambios entre prácticas reflexivas, interpretativas y críticas no sólo permitirá "ejemplarizar" y expandir una dinámica constructiva, esencial e inherente al desarrollo del pensamiento semiótico. También podrá generar aportes concretos a las prácticas didácticas e investigativas aplicadas (y sólo para citar un caso) al campo audiovisual, favoreciendo así una acabada comprensión de los fenómenos de transposición discursiva y textual ${ }^{9}$.

\footnotetext{
${ }^{9}$ Al respecto, ver más adelante el punto "2.3. Travesías del documental", donde exponemos una propuesta inicial para el abordaje de determinados "textos fílmicos".
} 
Considerando ahora la cuestión en términos más amplios, pensamos que los resultados del proyecto podrán contribuir al desarrollo de nuevas ideas sobre la enseñanza en general (de la enseñanza del campo, en particular), concebida como un fenómeno sociocultural (de singular y compleja naturaleza, socialmente construida) y como una acción intencionada, a la vez global y contextualizada (regida por reglas personales y sociales, y no tanto por leyes científicas). En consecuencia, dichos aportes tenderían a reconceptualizar cuestiones relativas a la índole epistémica y metodológica, a los fines y objetivos de una investigación educativa anclada (en ciertos casos, al menos) en andamiajes empíricos-analíticos, y más bien preocupada (todavía) por explicar las leyes de la eficacia docente.

La indagación narrativa propuesta (que parte de la revisión del "constructo relato", y se aplicará al estudio de casos puntuales: construcciones metodológicas, documentos curriculares, textos específicos de- y en- la clase...), también se articula con los presupuestos de una investigación interpretativa y crítica, de corte antipositivista, que procura comprender las conductas humanas desde los significados(a menudo sobreentendidos) e intenciones (muchas veces implícitas) de los sujetos (actores) sociales que interaccionan en el ámbito educativo.

La virtual comprobación, finalmente, de que ciertas actividades y efectos narracionales o enunciativos, por ejemplo, podrían operar como principios constructivos de diferenciación estructural (entre textualidades diversas) permitiría también fundamentar necesarios deslindes sobre extensiones habituales, al dominio audiovisual (por seguir con el mismo caso), de indagaciones efectuadas por la teoría literaria, o a la inversa. Asimismo, establecer distintas bases o criterios para categorizar, reconceptualizar o formalizar nuevas clasificaciones, tipologías...

\subsection{DE LOS SEMINARIOS DEL PROYECTO}

Teniendo una vez más en cuenta la singular naturaleza del objeto de indagación propuesto y sus específicas configuraciones (inter/trans) disciplinares, así en lo teórico como en lo metodológico, la formación de nuevos recursos humanos para la investigación, la docencia y la extensión se ha constituido en uno de los propósitos esenciales del desenvolvimiento de esta etapa del proyecto general, extensivo a las siguientes.

Al respecto se han desarrollado, con la denominación genérica de Seminarios de investigación, un conjunto de actividades sistemáticas relacionadas 
con la capacitación y perfeccionamiento de nuevos integrantes incorporados al equipo, con la actualización de sus saberes y conocimientos, y la producción e intercambio de diferentes tipos de experiencias, prácticas y resultados vinculados con la investigación, la docencia y la extensión en el dominio de las humanidades y las ciencias sociales. A partir de estos lineamientos, dichas programaciones aspiran a constituir progresivamente un espacio institucional de producción científica, a la vez que de intercambio y discusión permanentes, abierto a la comunidad: en el que, además de los miembros del equipo, puedan participar también investigadores de proyectos afines, otros docentes, graduados o alumnos interesados, y demás especialistas invitados.

En el primer Seminario (2000-2001) ${ }^{10}$, además de la realización de actividades complementarias sobre lecturas previas (síntesis expositivas, comentarios crítico-interpretativos, resolución de problemas, etc.) para favorecer el conocimiento y la comprensión del repertorio bibliográfico indicado, se abordaron temáticas y problemas específicos vinculados con determinados ejes conceptuales y metodológicos del proyecto. A través de las respectivas exposiciones (individuales o grupales) de los participantes en el Seminario, acerca de cuestiones y aspectos relacionados con cada eje temático, el análisis de casos y otras actividades de reflexión crítica (debate y producción grupal en torno a núcleos problemáticos de cada eje planteado), fueron tratados entre otros los siguientes temarios ${ }^{11}$ :

> La producción de conocimientos en el campo de las humanidades y las ciencias sociales: problemas lógico-empíricos y técnicas de investigación; relación entre diferentes abordajes metodológicos. Las perspectivas teóricas críticas.

\footnotetext{
${ }^{10}$ Los nuevos integrantes del equipo (investigadores en formación, auxiliares, becarios, tesistas, adscriptos y demás colaboradores del proyecto) suelen ser, en la mayoría de los casos, alumnos avanzados o egresados recientes de distintas carreras que se cursan en la Facultad de Humanidades y Ciencias de la Universidad Nacional del Litoral. Además de los profesores, docentes investigadores del equipo inicial de gestión del proyecto, participaron en este Primer Seminario de capacitación y actualización.

${ }^{11}$ Teniendo en cuenta la complejidad y dificultades propias de algunos de los ejes temáticos seleccionados (por ejemplo perspectivas 'críticas' de la teoría social, construcción del discurso en ciencias sociales, la cuestión referencial y el problema de la narratividad, etc.), los mismos fueron retomados y profundizados en nuevas versiones de este seminario inicial.
} 
$>$ Orientaciones de la investigación didáctica; estrategias cuanti y cualitativas; modelos teóricos y metodológicos. El análisis de las prácticas de la enseñanza. Estudio de casos y formulación de proyectos.

$>$ Aportes e intersecciones de diferentes teorías sociales en la construcción de las prácticas de la enseñanza, el aprendizaje y la investigación.

$>$ La construcción del discurso como objeto de las ciencias sociales. Los debates teóricos sobre los modos de representación y construcción del conocimiento. La cuestión referencial y el problema de la narratividad.

$>$ Implicaciones del denominado Giro lingüístico, la perspectiva semiótica textual y los desarrollos de la narratología.

$>$ De las perspectivas formalistas a la ruptura del paradigma narratológico estructuralista. Las narrativas didácticas e investigativas, y las componentes sintácticas, pragmáticas y semánticas del relato: pertinencias de su transposición.

La visión crítica que supone la perspectiva semiótica textual y el rico potencial teórico y analítico que aporta la narratología actual (su instrumental metodológico, incluso, para la explicación y comprensión de determinadas instancias de la enseñanza y la investigación socioeducativa, por ejemplo) garantizan y, en buena medida legitiman, la posibilidad de construir estrategias de indagación singulares y convergentes. Dichas herramientas podrían ser así reinterpretadas a la manera de un prisma, a través del cual sería posible reconstruir parte del amplio espectro de significaciones que proliferan en toda situación didáctica o investigativa, que desde entonces habría de ser concebida como un (inter)texto ${ }^{12}$. Incluso, según posturas intertextuales más radicalizadas (de acuerdo con las cuales la intertextualidad puede ser considerada como condición fundante no sólo de lo literario, sino también de toda escritura y de todo discurso, obviamente incluidos los discursos didáctico e investigativo), ningún texto individual es -en sentido estricto- único, ni puede ocupar una posición privilegiada con

\footnotetext{
${ }^{12}$ Las nociones de intertexto e intertextualidad habrían de constituirse en las dimensiones teóricas y analíticas fuertes del presente (y siguiente) tramo de la investigación en curso. Acerca de su incidencia en las reformulaciones del proyecto en desarrollo, y para la construcción de tres trayectos posibles de investigación narratológica aplicada, desde las discusiones del segundo Seminario, ver a continuación el ítem "2.2. Las narrativas en cuestión".
} 
respecto a algún otro. Esto resultaría así, dicho en términos teórico-conceptuales, debido a la urdimbre discursiva que entretejen las diferentes hebras del texto, lo cual cobra una importancia tal que, o bien el texto se contrae hasta devenir un mero nudo en la red intertextual, o bien se expande hasta abarcar la vastedad de sus interrelaciones con otros textos ${ }^{13}$.

Sobre el debate y (permanente) puesta en cuestión de estos mismos presupuestos, el segundo Seminario de investigación del Proyecto, que habría de desarrollarse en nuestra Facultad entre los años 2002-2003, estuvo motivado por el propósito de contextualizar, demarcar y enmarcar tres posibles trayectos investigativos que permitieran generar nuevos recorridos, alternativas y modos (deconstructivos e interpretativos) de abordaje de la cuestión, tanto en el campo específico de las indagaciones didácticas como en el dominio general de los estudios socioculturales. Al mismo tiempo, por la intención de profundizar críticamente en las múltiples dimensiones que se entrecruzan, por ejemplo, en la constitución del hecho educativo (incluidas la "realidad pedagógica": su compleja urdimbre en lo institucional y en el más allá de la escuela).

Los tres trayectos de investigación resultantes fueron inicialmente denominados, aunque en términos provisorios, como

$>$ Cruces, desvíos o confrontaciones entre pensamiento narrativo y otras constituciones de la teoría social.

> La cuestión narrativa en la selección bibliográfica (representaciones textuales del pasado reciente y trayectorias de vida).

> Travesías narrativas del filme documental (modalidades, estrategias, efecto referencial) ${ }^{14}$.

\footnotetext{
${ }^{13}$ Entre los polos de dicha alternancia podrán fluctuar, casi seguramente, los primeros avances de la siguiente etapa investigativa del proyecto.

${ }^{14}$ Con una denominación equivalente, el trayecto propuesto ha pasado a constituir además uno de los Proyectos para la Formación de Recursos Humanos en investigación y extensión (ProlnEx), convocados por la Secretaría de Ciencia y Técnica de la Facultad de Humanidades y Ciencias en abril de 2003.
} 
Entre las propuestas y producciones en curso de su tercera versión (años 2003-2004), el actual Seminario sobre Semióticas/Narrativas ${ }^{15}$ aspira a consolidar los aportes obtenidos durante su etapa anterior, a la vez que programar el dictado (durante el año 2005) de un Seminario-Taller de Investigación Semiótica sobre Narrativas Audiovisuales que, con carácter experimental, será ofertado como actividad académica de grado para diferentes carreras de la Facultad de Humanidades y Ciencias.

En su formulación actual, las actividades inicialmente programadas se orientarán en función de los siguientes propósitos fundamentales:

$>$ Reconocer diversos aportes de la narratología general, y profundizar en sus contribuciones al desarrollo de diferentes dominios disciplinares.

$>$ Explorar las posibilidades de consolidar una teoría narratológica aplicada al estudio del discurso audiovisual, en tanto orientación específica de la semiótica del cine.

$>$ Revisar y recrear, desde una perspectiva crítica sus principales presupuestos, dimensiones y categorías analíticas e interpretativas.

$>$ Indagar problemas generatrices de la divulgación científica y transponerlos al abordaje semionarrativo y discursivo de los denominados textos fílmicos documentales. $>$ Desarrollar diversas prácticas de lectura textual, con el objeto de confrontar y validar los resultados obtenidos en la construcción del marco teórico-explicativo y analítico. $>$ Diseñar proyectos investigativos y propuestas de transposición o mejoramiento didáctico, en relación con los aspectos temáticos y metodológicos abordados en el Seminario-Taller.

\section{LAS NARRATIVAS EN CUESTIÓN}

Aunque expresado en términos esquemáticos, el objeto-núcleo de nuestro Proyecto podría ser representado (gráficamente) como un triángulo cuyos

\footnotetext{
15 Para la ejecución de las actividades previstas, incluido el desarrollo del octavo tramo del proyecto general de investigaciones semióticas (en trámite de evaluación), se constituyó un equipo integrado por los docentes investigadores, tesistas, tesinistas, becarios y pasantes / adscriptos de los Profesorados y Licenciaturas en Letras e Historia.
} 
vértices, equidistantes e interconectados, equivaldrían a las tres principales orientaciones disciplinares que articula la propuesta. Dichos vértices, entendidos como ejes temáticos pero también como dimensiones teórico-metodológicas del proyecto serían los siguientes:

semiótica

enseñanza

investigación perspectiva semiótica

o bien

recorrido narratológico

La superficie triangular (el núcleo problemático y/o centro de interés de la propuesta, es decir el espacio en el cual y a través del cual interseccionan aquellos tres ejes) focalizaría entonces el discurso construido por el docente. Más precisamente: la construcción metodológica del discurso de su clase. O mejor aún: el texto mismo de la clase, en tanto que estructuración formal de ciertos contenidos $^{16}$ correspondientes a un dominio disciplinar específico y polémico, los saberes y conocimientos de las denominadas ciencias humanas y sociales.

${ }^{16}$ Obviamente, por tratarse de la proyección (al objeto observado) de una mirada o perspectiva semiótica, no me estoy refiriendo aquí sólo a los contenidos correspondientes al currículo de una asignatura. Vale establecer por ello un par de necesarias precisiones, que retomo de planteamientos ya efectuados:

1 > En la concepción lingüística de Hjelmslev, retomada por el semiotista Greimas, cuando un código asocia elementos de un sistema transmisor con elementos de un sistema transmitido, el primero se convierte en la expresión del segundo el cual, a su vez, se transforma en el contenido del primero. Existe función semiótica cuando una expresión y un contenido entran en correlación: ambos se convierten en funtivos de tal correlación. Cada uno de dichos planos del signo (la expresión y el contenido) admite a su vez ser entendido desde lo formal y lo sustancial. Coincidiendo con F. Saussure en que la lengua es forma y no sustancia, Hjelmslev postula que la forma semiótica es una invariante que da cuenta de la red relacional que define las unidades, y que la sustancia semiótica (materia o sentido), en cuanto soporte de la significación, es una variable. Es decir: una determinada forma (textual, discursiva, narrativa, por ejemplo) puede manifestarse a través de muchas sustancias (fónica, gráfica, gestual, audiovisual...), pero no a la inversa. 2 > Fundada en tales categorías, nuestra perspectiva de abordaje del objeto de estudio parte en consecuencia de dos supuestos fundamentales, relacionados entre sí:

a > Las construcciones discursivas de carácter didáctico no sólo podrían ser pensadas como estructuras funcionales, operatorias y transpositivas de distintos contenidos disciplinares específicos, sino también como un campo de estrategias discursivas que sostienen los sujetos que interactúan en la puesta-en-escena educativa, cuyas interacciones también producen específicos contenidos diferenciales, a menudo implícitos o sobrentendidos. b > El reconocimiento y análisis de tales procedimientos formales no sólo resisten la simplificadora interpretación 
Los resultados de la experiencia realizada durante el primer año del último tramo (su rentabilidad y, naturalmente, también sus dificultades) aconsejaron establecer desde entonces nuevos acotamientos y recortes en el proyecto inicial, así como privilegiar en la observación del objeto un determinado punto de vista entre otros posibles, que a su vez atravesara las diferentes componentes (triangulares) de este último diseño. Dicho atravesamiento, que connota una vez más las travesías del sentido que refiere la redenominación actual del proyecto, responde en realidad a una perspectiva múltiple de acceso al problema de las significaciones en el campo social y educativo: a una visión estereoscópica de aquel mismo objeto de estudio.

Quiero decir: la consideración de la clase (de humanidades y ciencias sociales) como un intertexto didáctico ${ }^{17}$ en el que resulte posible enmarcar una serie de trayectos discursivo-narrativos, dentro de los cuales se permita individualizar, analizar e interpretar alguno de los diferentes modos de transposición que siempre acontecen en toda situación didáctica.

de lo evidente, sino que permiten reflexionar sobre cuestiones que, en alguna medida, anteceden al efectivo funcionamiento de las prácticas empíricas (las cuales se sitúan en un contexto explícito, específico: el "aquí-y-ahora" de las prácticas, en un determinado contexto institucional educativo)

17 La noción actual de intertextualidad deriva de la concepción (inicial) de la obra literaria como un texto cuya riqueza y variedad de significados resulta de su posición (precisamente intertextual), localizada en una red o urdimbre significante, potencialmente infinita, constituida por la multiplicidad de otros textos.

Sin embargo, los estudios referidos a las problemáticas de la intertextualidad (inicialmente focalizados, como dijimos, en el campo de la literatura, con Kristeva, Barthes, Genette, Riffaterre, entre muchos otros autores), se han ido proyectando con posterioridad hacia otras artes y fenómenos culturales: el cine (Metz, lampolski), las artes plásticas (Calabrese, Steiner), la música (Chambers, Hatten), el teatro, la televisión, etc. Así, durante las tres últimas décadas, un desarrollo sostenido de la noción de intertextualidad, acompañado de oportunas discusiones teóricas y aplicaciones analíticas, han originado una abundante bibliografía, producida en numerosas lenguas (ver, además de los autores mencionados: Derrida, Culler, Segre, Hempfer, Angenot, Ruprecht, Grivel, Krysinski, Arrivé, Dällenbach, Glowinski, Jenny, Zumthor, etc.). Inclusive, tal vez debido a las estrechas relaciones que pueden establecerse entre el fenómeno intertextual y ciertas tendencias y problemáticas teóricas de máxima actualidad (posmodernismo, posestructuralismo, deconstruccionismo, metaficción, interculturalismo...), en los últimos años se han revitalizado estas discusiones y sobredeterminado la vigencia y actualidad del tema, haciendo que el interés por la intertextualidad se extienda (también ahora) a líneas investigativas más recientes como la construcción del discurso de la oralidad o los estudios feministas, postcoloniales, raciales, multiculturales, etc. 
En este sentido, los rediseños o reajustes posteriores del proyecto (incluidos algunos replanteos conceptual-operatorios de la investigación en curso ${ }^{18}$, y un nuevo esquema funcional-organizativo de sus principales actividades ${ }^{19}$ ), propios de la dinámica de todo proceso de investigación, no pretendieron invalidar o rectificar lo anteriormente realizado, sino recuperarlo y enriquecerlo a partir de una nueva opción y recorte teórico-metodológico practicado sobre la propuesta original.

Es decir: proyectando nuevos abordajes sobre el problema, en relación por ejemplo con el estudio de los siguientes tópicos:

1 > las configuraciones narrativas implícitas que condicionan y regulan la construcción por el docente de la perspectiva teórica (a veces invisible o imprevista) de una clase; 2 > los itinerarios (sintáctico-semánticos: otra vez narrativos) que recorre el discurso del docente en procura de reconstituir los saberes y conocimientos, a través de la práctica educativa;

3 > las estrategias (pragmáticas) por las cuales se establece el contrato didáctico y se prefiguran (otra vez en términos narrativos) los espacios referenciales de la clase; $4>$ los discontinuos relatos co(n)textuales que conjuntan en una precisa circunstancia didáctica (prácticas institucionales, discursos del "más allá de la escuela", etc.).

Con estos avances (fundamentales, pero sólo preliminares) en cuanto a la redefinición y explanación del entorno conceptual pretendido, quisiéramos proceder ahora a delimitar o recortar y ejemplificar (reconocer, describir, comprender, etc.) diferentes configuraciones narrativas a través de un estudio sistemático de

\footnotetext{
${ }^{18}$ En un documento de trabajo que preparara a fines del año 2002, al que denominé "Rediseños del proyecto. Trayectos de la investigación en curso" (inédito) se recuperan los principales lineamientos, ejes y objetivos del proyecto original (1999), y se fundamentan los posteriores ajustes y redefiniciones producidos en su encuadre conceptual-metodológico inicial. Asimismo, se delimitan y caracterizan en dicho documento los trayectos de investigación que habrían de constituir la agenda de trabajo del tramo actualmente en ejecución.

${ }^{19}$ A partir de la presentación y discusión del documento mencionado en la nota anterior, se vinieron desarrollando seminarios de investigación (ver al final de "2.1. El proyecto en perspectiva") relacionados con programación de carácter sistemático y permanente, orientadas a la capacitación y perfeccionamiento de nuevos recursos humanos, a la actualización de sus saberes y conocimientos, y a la producción e intercambio de diferentes tipos de experiencias, prácticas y resultados vinculados con la investigación y la extensión en lo social y educativo.
} 
casos. También, a analizar e interpretar algunos de sus mecanismos y soportes (configurativos) y principales procesos de desciframiento (textual discursivos).

La tarea prevista para el futuro inmediato, en la dirección antes indicada, también se articula con incipientes desarrollos obtenidos a propósito del diseño de tres trayectos de investigación propuestos (una vez más) durante la etapa anterior:

$>$ Uno de los trayectos se ha aplicado inicialmente a las representaciones del pasado histórico reciente y sus efectos de sentido en los textos escolares de educación básica. Desde allí ha permitido efectuar nuevas exploraciones acerca de las formas de recepción textual en los manuales de estudio, posteriormente enriquecidas con los aportes de distintos relatos testimoniales referidos en sucesivas entrevistas realizadas durante el trabajo de campo. En la próxima fase se abordará la construcción textual de la entrevista como forma particular de narrativa, cuyo principal valor deriva precisamente de la puesta-enescena (de la puesta en sentido) de una subjetividad que permite acceder al entretejido de relaciones establecidas entre los dos universos (personal y social) existenciales del sujeto. $>$ El segundo recorrido previsto (por diversas razones de orden teórico, epistémico y metodológico, en fase actual de diseño y planificación) tiene que ver con el reconocimiento de cruces, desvíos o confrontaciones operantes entre pensamiento narrativo y otras constituciones de la teoría social, a partir de la discusión y reenfoque de algunos de los tópicos más polémicos existentes en la actualidad del campo: tal el caso, por ejemplo, de las problemáticas de la narratividad y la referencialidad en el dominio de los modos de construcción y representación del conocimiento social. $>$ Asimismo, el tratamiento de diferentes cuestiones teóricas, analíticas y críticas relacionadas con la producción, consumo y mejor aprovechamiento didáctico de los denominados textos fílmicos documentales (en particular, los que se consideran documentales de divulgación científica), inicialmente orientados a la develación y desmontaje de los itinerarios semio-narrativos y discursivos que los constituyen, orientan el desarrollo de nuestro tercer trayecto investigativo, el que se evalúa como especialmente apropiado para la formación de nuevos recursos humanos en actividades de extensión e investigación específicas del campo ${ }^{20}$.

\footnotetext{
${ }^{20}$ Por tales razones, atendiendo a la singular naturaleza del objeto de indagación propuesta y sus específicas configuraciones inter/transdisciplinares, así en lo teórico como en lo metodológico, incorporo en el siguiente apartado (y a modo de ejemplificación) los lineamientos generales del mencionado trayecto. Ver ítem "2.3. Travesías del documental".
} 
La construcción de estos andamiajes teórico-explicativos permitirá delimitar y focalizar (como decía antes) un conjunto de específicas configuraciones narrativas resultantes de un estudio sistemático de casos. Dicho estudio se habrá de orientar (al menos en sus inicios, y con carácter experimental) al abordaje de determinadas prefiguraciones narrativas (de microrrelatos explícitos o virtuales, de breves acontecimientos discursivos con improntas de registro narrativo...), localizadas en distintos materiales-objetos de trabajo.

Entre otras variables textuales del corpus analítico en constitución merecen citarse, por ejemplo, el análisis e interpretación de situaciones didácticas e investigativas, la reconstrucción de experiencias o de prácticas docentes, y sus correspondientes construcciones metodológicas, la relectura crítica de textos especializados o materiales de divulgación, informes de investigación, documentos curriculares, manuales de estudio...; así como la descripción y comprensión de diferentes narrativas audiovisuales, en particular aplicadas a los denominados documentales de divulgación científica, etc. ${ }^{21}$

A manera de diversos ejemplos quisiera citar (en su estado actual de formulación, provisoria y tentativa, incluso previo a los procesos ulteriores de transposición didáctica y/o investigativa) las siguientes propuestas particulares de estudio, reordenadas u organizadas en función de cuatro problemáticas básicas:

1 > La cuestión de los soportes estructurales específicos que identifican a los denominados discursos audiovisuales, mediante el abordaje de los principales dispositivos textuales y estrategias narrativas, enunciativas y perceptivas que los caracterizan. Esa indagación se orientará, por ejemplo (y sólo en principio), de acuerdo con diferentes propuestas de trabajo:

\footnotetext{
${ }^{21}$ Unas y otras cuestiones serán abordadas, durante la ejecución del siguiente tramo del proyecto, a través del desarrollo simultáneo de diversas líneas o propuestas particulares de trabajo, las que estarán a cargo de los respectivos docentes investigadores e investigadores en formación del equipo (tesistas, becarios, adscriptos, etc.). Los aportes y contribuciones parciales, convergentes o divergentes de dichos trayectos particulares serán recuperados, revisados y articulados en función del propósito conjunto, a partir de las reuniones de coordinación grupal que ya se vienen efectuando, con una periodicidad semanal o quincenal, en la sede de la Facultad de Humanidades y Ciencias.
} 
$>$ Los mecanismos de traducción intersemiótica puestos en juego en zonas fronterizas reconocibles entre las narrativas literaria y cinematográfica (analizando algunos modos en que determinadas narrativas del cine argentino, por ejemplo, se apropian del fenómeno literario, y/o el impacto de lo cinematográfico en las narrativas literarias contemporáneas).

$>$ El filme documental como constructo semiótico-discursivo que despliega un conjunto de representaciones sociales, culturales y didácticas (un caso particular, el del documental biográfico, será abordado por ejemplo desde propuestas convergentes del análisis del discurso y la teoría de las ideologías).

$>$ Las relaciones posibles entre el discurso científico y el lenguaje audiovisual, en el caso de los documentales de divulgación científica por ejemplo, con el objeto de proponer modos de elaboración de tipologías posibles, fundadas en las pertinencias que establece el proyecto.

2 > Una segunda línea de investigación indagará en la posibilidad de establecer relaciones entre teorías narratológicas y teorías sociales (específicamente, en determinadas tematizaciones y eventuales soportes narrativos de ciertas teorías):

$>$ Por un lado se propone reenfocar algunos tópicos polémicos en el campo del pensamiento social, como lo es la problemática acerca de la narratividad y la referencialidad, en cuanto modos de construcción y representación del conocimiento social (particularmente en la teoría habermasiana).

$>$ Por otro, se adoptarán como objeto las condiciones escriturarias que la teoría social objetiva a modo de referente, y que se actualiza en cada producción (por ejemplo, mediante una aproximación a la narrativa como operatoria de sentido en la teoría de Bourdieu).

$>$ También se propone conocer y reconocer la memoria como exigencia de construcción del presente a través del análisis narrativo de las huellas de la historia (esto es: la indagación crítica sobre la génesis de memoria, historia, sociedad y política, capaz de dar cuenta de las construcciones de sentido y de las luchas por su imposición, que operan en el tópico). 
3 > Una tercera línea de investigación narratológica propone abordar la entrevista como forma particular de narrativa (lo que impondría tomar en cuenta su específico carácter, en relación con lo personal y lo social, reconocer la memoria como proceso de creación de significados y los modos en que el contexto de emisión condiciona los relatos testimoniales).

4 > Otra línea de indagación pretende abordar, finalmente, las tecnologías de la información y las comunicaciones, por donde circulan textos electrónicos de carácter hipermedial (como creadores de nuevos sistemas de codificación y decodificación de la información), que permitirían redefinir la noción de narratividad en el contexto de la era global.

\section{TRAVESÍAS DEL DOCUMENTAL}

El planteamiento y resolución de diferentes cuestiones teóricas, analíticas y críticas relacionadas con la producción y consumo de los denominados textos (fílmicos) documentales centralizaron el interés de una propuesta investigativa particular en la nueva etapa de desarrollo del Proyecto de semiótica. Desde su concepción, este Trayecto, inicialmente denominado Travesías narrativas del documental (modalidades, estrategias, efecto referencial), se proponía indagar $^{22}$ en la singular construcción semionarrativa y discursiva de diversas manifestaciones del cine documental y en sus específicos modos de abordaje, transposición y posible aprovechamiento didáctico.

Qué es un film documental, cuál es su especificidad constitutiva y genérica en el contexto de las narrativas audiovisuales; de qué manera construye sus significados (representa y/o re-significa objetos, aspectos o comportamientos de la "realidad"); a partir de qué supuestos sería posible tipologizarlo; cómo puede ser leído, descripto e interpretado, y (a la vez) mejor aprovechado en

\footnotetext{
${ }^{22}$ La primera versión de este documento fue preparada para su discusión en jornadas iniciales del Seminario 2003 del proyecto sobre semióticas/narrativas, a fin de ser debatida y enriquecida con los aportes de nuevos recursos humanos para la investigación y la extensión (graduados y alumnos) recientemente incorporados al equipo del proyecto.
} 
concretas situaciones de enseñanza y de aprendizaje escolar..., se nos aparecían (ya, desde entonces) como interrogaciones centrales de una motivadora y productiva propuesta de investigación y desarrollo.

En dicha concepción, el principal objetivo de una teoría y pedagogía críticas de la producción audiovisual (el documental incluido) debiera ser mostrar cómo las organizaciones e instituciones, los equipos creativos y aun los públicos receptores, consumidores de imágenes, construyen determinados significados a través de sus prácticas, mediante un particular trabajo de representación icónica. Es decir: propiciar una lectura crítica del texto audiovisual (direccionar el análisis e interpretación de un documental, por ejemplo) debiera consistir, básicamente, en desmontar la aparente naturalidad de las imágenes, en discutir la supuesta transparencia de su proceso de producción.

En tanto que sistema (específico) de representación, todo documental podría ser así considerado como la evidencia o manifestación (textual) de un dinámico proceso de formalización de ciertas categorías significativas, a menudo implícitas o subyacentes... Como la forma (específica) de un contenido, en definitiva: de una construcción narrativa y discursiva que conceptualiza, clasifica y organiza reglas, comportamientos y convenciones sociales que se traducen en diferentes prácticas (culturales, institucionales, estéticas, políticas, etc.) desarrolladas en determinados contextos.

Teniendo en cuenta que tales regularidades, códigos y convenciones no se limitan, en el caso del film documental, a lo que habitualmente se concibe como el contenido de una película ("lo representado"), sino que abarca al cómo se construye ese contenido ("el sistema de representación"), nuestro abordaje del objeto de estudio procurará dar cuenta a la vez de tres contextos de manifestación (concebidos como tres instancias de permanente interacción y negociación de significados):

$>$ las circunstancias de producción textual (contexto de enunciación);

$>$ la conformación semiótico-estructural del texto (interacciones texto/contextos), y

$>$ los niveles de consumo, reconocimiento y audiencia (contexto de recepción textual).

Considerada entonces en términos de semiótica textual, la índole narrativa de nuestro objeto-problema podría ser así reconstruida a través de un complejo 
recorrido generativo de significaciones que, a partir de estructuras subyacentes de sentido, aflora o se manifiesta a través de un proceso de productividad en el que se articulan e interactúan diferentes componentes del contenido y de la expresión fílmicas: acciones, personajes, espacios, tiempos, enunciaciones, focalizaciones (iespecíficas?) del documental.

Dichas travesías narrativas del sentido(modalidades, estrategias y efectos de este proceso configurativo del objeto-texto-documental) podría ser analizada e interpretada, según nuestra hipótesis inicial, desde (por lo menos) seis perspectivas teórico-explicativas complementarias de abordaje: desde una analítica, una morfología, una taxonomía, una poética, una retórica y una pragmática textual (Jiménez, 1996).

> La perspectiva analítica se ocuparía de identificar las unidades del sistema y del proceso fílmico documental y de detectar el comportamiento funcional e interactivo de las mismas.

$>$ La perspectiva morfológica procuraría caracterizar los patrones u observables que constituyen la particular estructura (sintagmática) del texto documental.

La perspectiva taxonómica permitiría clasificar y tipologizar o, por lo menos, establecer algunos parámetros o principios de organización paradigmática del corpus.

> Las perspectivas poética y retórica favorecerían la reflexión acerca de las normatividades caracterizadoras del complejo textual (lo invariable), y también sus variantes estratégicas y estilísticas. Esto es, lo creativo y lo transgresor en el documental: las operaciones retóricas que lo enriquecen, las posibles lecturas interpretativas que lo abarcan, etc. > La perspectiva pragmática, finalmente, por situarse en un paradigma de comunicabilidad textual, permitiría estudiar las diferentes relaciones existentes entre los signos del film documental, sus potenciales intérpretes y usuarios empíricos.

En su primera fase, el presente trayecto aspira a recopilar, reconceptuar y construir un corpus suficiente de saberes teórico-metodológicos que permita, por un lado, caracterizar o legitimar (conceptual y prácticamente) la índole específica del filme documental y, por el otro, analizar y validar (con criterio 
científico) las propuestas de lectura practicadas sobre el corpus textual conformado al efecto. Sometidos a evaluación crítica los resultados de esta primera etapa, se pretenderá en una segunda transponer sus eventuales contribuciones a otros contextos: acaso, como aportes al desarrollo de los procesos denominados de alfabetización audiovisual, o al mejoramiento de las prácticas didácticas en diferentes instancias de la educación formal y no formal.

Se prevé desarrollar la fase inmediata, preliminar del trayecto, mediante la ejecución de distintas actividades ordenadas en función de cuatro ejes de tratamiento, los cuales serán abordados de manera simultánea. Las tareas relacionadas con el primero de los ejes tendrán que ver, especialmente, con el relevamiento sistemático y la compatibilización crítica de los referentes bibliográficos disponibles, tanto sobre principales orientaciones de la investigación desarrollada en el dominio cinematográfico, cuanto acerca de sus antecedentes en el campo específico de la teoría y el análisis del film documental. El cotejo de la bibliografía general no sólo permitirá sistematizar contribuciones de diferentes autores y los aportes de diversas disciplinas, indispensable para un debate semiótico acerca de los desarrollos actuales de la investigación cinematográfica ${ }^{23}$, sino también reconstituir un repertorio lexicográfico relativamente exhaustivo con los conceptos teóricos más frecuentemente aplicados al cine en las últimas décadas. La recopilación crítica de la bibliografía específica permitirá dar cuenta de contribuciones existentes acerca de posibles dimensiones y categorías analíticas e interpretativas del documental, de sus modalidades y estrategias de representación, y sobre otras problemáticas vinculadas con espacios de reflexión afines: la responsabilidad ética y los planteamientos ideológicos, los aspectos lógicos y argumentativos, las cuestiones del realismo y la objetividad, etc. (cfr. Altman, 2000; Jost, 2002; León, 1999; Nichols, 1997; entre otros).

Al respecto, buena parte de la reciente bibliografía sobre el tema ha puesto el acento en el carácter presuntamente ficcional de los filmes documentales. Lo que se enfatiza es que (en la mayoría de los casos y más allá de sus diferentes versiones, soportes o formatos) los procesos de ficcionalización narrativa audio-

\footnotetext{
${ }^{23}$ Nota de Edición: ver al respecto, en el último artículo de la Parte III de nuestra compilación "Metamorfosis de lo originario (codas del informe)". Especialmente las referencias bibliográficas seleccionadas sobre problemáticas iniciales al abordaje del campo de las narrativas audiovisuales y los documentos de divulgación científica.
} 
visual adaptan, modulan o reformulan determinadas cuestiones de la realidad y ciertas experiencias de la vida cotidiana; así como los relatos documentales suelen incorporar tramas, personajes, situaciones, acontecimientos...para constituirse como tales estructuras textuales: plantean dilemas o carencias, recrean tiempos y espacios, construyen tensiones y conflictos, los resuelven y/o los clausuran, como cualquier otra ficción.

A pesar de que consideramos arbitraria y falaz la dicotomía planteada entre film documental y film de ficción, y que ambas modalidades no son ni reductibles ni alternativas, sino complementarias, el segundo eje de abordaje de nuestra propuesta revitalizará la tradicional discusión "ficción / realidad" en el interior del concepto de representación audiovisual, revisará sus presupuestos y argumentará sus fundamentos.

Asimismo, para permitirnos integrar ambas prácticas en términos polémicos y dialógicos (es decir, más que como discursos diferentes como modalidades distintas de operar en el interior de una misma formación discursiva), se repondrá el problema a partir de la reconstrucción de espacios referenciales (históricos, geográficos, costumbristas...) similares o aparentemente idénticos, así como los mismos son representados, ya sea en filmes ficcionales, ya sea en películas documentales.

La tercera perspectiva de indagación sitúa la problemática de nuestro objeto tal vez en su sentido más específico, propio y restringido: el hipotético anclaje narrativo del film documental. Las actividades previstas en esta dirección procurarán recuperar y articular, mediante operatorias sintéticas y sincréticas, aportes de la teoría y la práctica narratológica en general, así como diferentes avances desarrollados en el campo de las narrativas audiovisuales en particular, para verificar posibilidades concretas de asimilación, adaptación y/o transpolación de resultados ya obtenidos, a la lectura de los documentales del corpus.

Este reordenamiento metódico, sistemático y crítico de los saberes y conocimientos existentes en el dominio, y el relevamiento de sus principales constructos y categorías analíticas, permitirán descubrir, describir, explicar y comprender el sistema, el proceso y los mecanismos de narratividad que interactúan en la específica construcción audiovisual del texto fílmico documental, tanto en su forma como en su funcionamiento. 
Con las actividades del cuarto nivel de abordaje de la cuestión, se procurará finalmente examinar, validar y articular (a través del ejercicio mismo de las lecturas practicadas sobre las componentes del corpus) un conjunto de procedimientos analíticos e interpretativos, con la intención de revisar el estatuto discursivo del comentario crítico (que a menudo se proyecta) sobre los filmes documentales, y de proponer una operatoria metodológica específica para investigar los objetos del campo.

Sin excluir los intereses sociales e ideológicos que caracterizan a la industria y la producción cinematográfica (ni tampoco los aspectos culturales, estéticos, económicos y políticos que se inscriben en la textura enunciativa de cada objeto fílmico particular), sino recuperándolos en función de una perspectiva analítica integradora, la película documental será entonces (así) considerada...como un aparato textual posible de ser:

$>$ deconstruido mediante diferentes procesos de descomposición y recomposición; $>$ descripto en su modo de funcionamiento estructural;

$>$ comprendida su significación, en tanto articulación (narrativa y discursiva) de las componentes que lo constituyen como tal objeto; $y$

$>$ justificada la lectura o interpretación producida, en términos de propuesta direccional de un sentido (textual) determinado. 